\title{
Elevated Serum Lipase Levels in Patients with Dyspepsia of Unknown Cause in General Practice
}

\author{
Rieko Okada $^{a}$ Akira Okada $^{b}$ Takashi Okada $^{b}$ Tohru Okada $^{b}$ \\ Nobuyuki Hamajima ${ }^{a}$ \\ ${ }^{a}$ Department of Preventive Medicine/Biostatistics and Medical Decision Making, Nagoya University \\ Graduate School of Medicine, and b Okada Medical Clinic, Nagoya, Japan
}

\section{Key Words}

Dyspepsia $\cdot$ Lipase $\cdot$ Pancreatic disorder

\begin{abstract}
Objective: To study the cause(s) of chronic dyspepsia among patients with no findings on general practice screening tests. Materials and Methods: A total of 272 consecutive patients at a general practice in Japan (125 males and $147 \mathrm{fe}-$ males, aged 14-89 years) who underwent abdominal ultrasound (US) and who had serum pancreatic enzyme (lipase or p-amylase) levels measured, were included in a 1-year study. Serum pancreatic enzyme levels were compared according to the duration of the symptoms and causes of dyspepsia, and then compared between two groups: a 'known-cause group' of 38 patients in whom the cause of the chronic (over 1 month) dyspepsia was determined by US or other diagnostic procedures; and an 'unknown-cause group' of 112 patients in whom no cause was found. Results: The mean lipase level in the unknown-cause group was significantly higher than that in the known-cause group ( 40.6 vs. $35.3 \mathrm{U} / \mathrm{l}$, $p=0.008$ after adjustment for age, sex, and serum creatinine). No difference between these groups was found for $p$ amylase. The proportion of patients with high lipase levels (above reference range) was higher in the unknown-cause group compared to the known-cause group, although this
\end{abstract}

\section{KARGER}

Fax +4161306 1234

E-Mail karger@karger.ch

www.karger.com
(C) 2009 S. Karger AG, Basel

1011-7571/09/0182-0130\$26.00/0

Accessible online at:

www.karger.com/mpp was not significant (21.4 vs. $10.5 \%)$. Conclusion: Our data showed that serum lipase levels were higher in patients with chronic dyspepsia of unknown than in those with a known cause. We therefore speculate that mild functional pancreatic disorder may underlie some cases with unexplainable chronic dyspepsia.

Copyright $\odot 2009$ S. Karger AG, Basel

\section{Introduction}

Dyspepsia, defined as pain or discomfort centered in the upper abdomen, is common in the general population, accounting for $2-8 \%[1,2]$ of consultations with general practitioners. There are several causes of dyspepsia, including motility disturbances [3], abnormal visceral sensitivity [4] and hormonal changes [5]. However, in most cases the cause is unknown. Some studies have documented abnormal pancreatic function in patients with dyspepsia. The exocrine pancreatic function, assessed on the basis of lowered duodenal concentrations of lipase and amylase after a high-fat test meal, was abnormal in about one third of patients with dyspepsia [6, 7], and lowered tryptic activity was seen in one third of patients with endoscopically confirmed non-ulcer dyspepsia unrelated to alcohol intake [8]. In primary care, abnormally low 
Fig. 1. Groups of study subjects according to the symptoms and causes of dyspepsia $(\mathrm{n}=272)$.

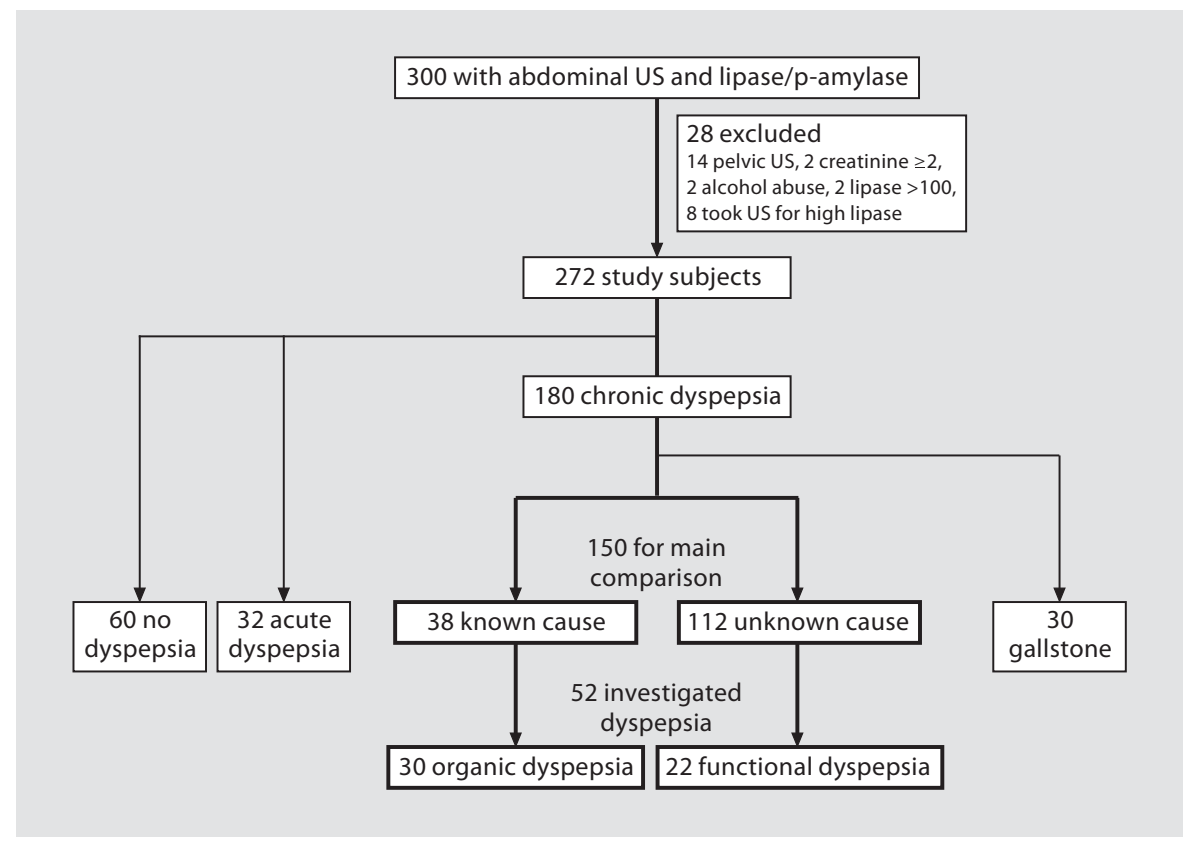

pancreatic enzyme levels were observed in $20 \%$ of dyspepsia patients [9]. Another study showed that the prevalence of endosonographic pancreatic abnormalities was higher in patients with dyspepsia than in control subjects, concluding that dyspepsia may be an atypical presentation of occult mild chronic pancreatitis [10].

Functional dyspepsia is defined as the presence of dyspepsia symptoms in the absence of any organic, systemic or metabolic disease that is likely to explain the symptoms [11]. The recommended treatments for functional dyspepsia are a low-fat diet [12], H2 blockers and proton pump inhibitors [13], and sometimes pancreatic enzyme supplements [14]. These treatments are the same as those for chronic pancreatitis $[15,16]$.

We hypothesized that among patients with chronic dyspepsia of unknown cause in a general practice, some have a mild functional pancreatic disorder resulting in elevated lipase and/or pancreatic isoamylase (p-amylase) levels.

\section{Subjects and Methods}

\section{Study Subjects}

Initially, 300 subjects (144 males and 156 females, aged 14-94 years) were included, who underwent an abdominal ultrasound (US) and pancreatic serum enzyme testing (lipase and/or p-amylase) between July 2006 and June 2007 at the Okada Medical Clinic, a general practice in an urban area of Nagoya in central Japan.
Their medical records were examined retrospectively. Among these subjects, 28 were excluded: 14 underwent only pelvic US; 2 had serum creatinine levels of more than $2.0 \mathrm{mg} / \mathrm{dl}$; 2 were suspected of alcohol abuse; 2 had lipase or p-amylase levels of more than $100 \mathrm{U} / \mathrm{l}$ (1 patient was diagnosed with a possible acute pancreatitis and another with pancreatic cancer), and 8 asymptomatic patients were examined by US because of high lipase levels from their known pancreatic or biliary diseases. So, 272 subjects (125 males and 147 females, aged 14-89 years) were included in this study. None of these patients were receiving nonsteroidal anti-inflammatory drugs, or medications such as thiazides, cholinergic agonists or narcotics which may elevate serum lipase and p-amylase levels.

In those 272 patients, 180 showed symptoms of chronic dyspepsia; dyspepsia was defined as pain or discomfort centered in the upper abdomen, and excluded reflux symptoms according to the Rome criteria [11], and chronic dyspepsia was defined as the presence of dyspepsia for more than 1 month before undergoing abdominal US. Patients with no dyspepsia or symptoms of acute dyspepsia constituted the other groups. Among those with chronic dyspepsia, 30 comprised the gallstone group: patients with gallstones or a history of cholecystectomy and whose lipase or p-amylase levels could be elevated because of biliary congestion. Finally, 150 patients were divided into two groups: the 'known-cause group' consisted of patients in whom the dyspepsia symptoms were clarified by abnormalities seen on US, abdominal computed tomography (CT) or other diagnostic procedures, and the 'unknown-cause group' included patients with dyspepsia in whom no abnormalities were found (fig. 1).

\section{Data Collection}

In all study subjects the presence and duration of dyspepsia, as well as the history of cholecystectomy, were retrospectively ob- 
Table 1. Characteristics of study subjects according to the symptoms and causes of dyspepsia $(\mathrm{n}=272)$

\begin{tabular}{|c|c|c|c|c|c|c|}
\hline & No dyspepsia & Acute dyspepsia & \multicolumn{3}{|c|}{ Chronic dyspepsia } & $\mathrm{p}^{\mathrm{a}}$ \\
\hline Age, years & $69(63-75)$ & $55(36-63)$ & $66(57-75)$ & $66(57-75)$ & $70(62-79)$ & 0.782 \\
\hline Male, \% & 50 & 53 & 45 & 43 & 43 & 0.840 \\
\hline LDL cholesterol, mg & $126 \pm 31$ & $114 \pm 26$ & $119 \pm 30$ & $120 \pm 28$ & $125 \pm 29$ & 0.418 \\
\hline Fatty liver ${ }^{\mathrm{b}}, \%$ & 30 & 31 & 17 & 16 & 33 & 0.912 \\
\hline $\mathrm{HT}, \%$ & 51 & 24 & 21 & 23 & 38 & 0.779 \\
\hline DM, \% & 8 & 0 & 6 & 5 & 21 & 0.881 \\
\hline $\mathrm{HL}, \%$ & 10 & 3 & 9 & 5 & 14 & 0.451 \\
\hline Uric acid, mg/dl & $5.1 \pm 1.3$ & $4.7 \pm 1.4$ & $5.5 \pm 1.7$ & $5.3 \pm 1.4$ & $5.4 \pm 1.5$ & 0.231 \\
\hline Pancreatic degeneration, \% & 5 & 0 & 11 & 11 & 10 & 0.986 \\
\hline
\end{tabular}

Variables are presented as means $\pm \mathrm{SD}$, median (interquartile range) for age and triglyceride, or percentages.

a Student's unpaired t test, Wilcoxon rank-sum test, or $\chi^{2}$ test for the comparison between the known-cause group and the unknown-cause group.

${ }^{\mathrm{b}}$ Data were derived from 258 patients under abdominal CT examination. $\mathrm{TG}=$ Triglyceride; $\mathrm{HT}=$ hypertension; $\mathrm{DM}=$ diabetes mellitus; $\mathrm{HL}$ = hyperlipidemia; pancreatic degeneration = calcification or atrophic change of pancreas.

tained from medical records. The presence of gallstones, the diameter of the main pancreatic duct (MPD, dilatation defined as more than $2 \mathrm{~mm}$ ), and the diameter of the common bile duct (CBD, dilatation defined as more than $10 \mathrm{~mm}$ ), were obtained by abdominal US examination. The presence of fatty liver and degenerative pancreatic changes, like calcifications and atrophic changes, were determined by abdominal CT which was analyzed by radiologists. Upper gastrointestinal endoscopy or upper gastrointestinal tract imaging was performed by gastroenterologists depending on the patient's symptoms (for example, alarm symptoms such as fever, bleeding, anemia, or weight loss [11]). Serum lipase and p-amylase levels were determined by the colorimetric method and the immunoinhibition method (Lipase Color and AMY EPS; Roche Diagnostics, Tokyo, Japan) [17], respectively, on the day of abdominal US examination after a minimum 8-hour overnight fast. Levels above the reference range (higher than 50 $\mathrm{U} / \mathrm{l}$ ) were defined as high lipase and high p-amylase. Other biochemical tests, including measurements of the levels of serum LDL and HDL cholesterols, triglyceride, uric acid, creatinine and iron, were also performed on the same day. Patients receiving blood pressure-lowering drugs, glucose-lowering drugs, and lipid-lowering drugs were defined as having hypertension, diabetes mellitus and hyperlipidemia, respectively.

The total number of consultations at this clinic during the study period was determined to calculate the expected prevalence of patients who showed high lipase or high p-amylase levels among the unknown-cause group; in this study we defined these patients as having 'mild functional pancreatic disorder'.

\section{Subgroup Analysis among Patients with Investigated}

Dyspepsia

Some patients with chronic dyspepsia from both the unknown-cause group and known-cause group who had undergone upper gastrointestinal endoscopy or upper gastrointestinal tract imaging besides an US were further designated as the 'investigated dyspepsia' group [18] and further classified either as 'organic dyspepsia' of 'functional dyspepsia', according to the criteria of the 'known-cause group' and the 'unknown-cause group' (see 'Study Subjects'), respectively.

\section{Statistical Analysis}

The characteristics of the five groups (fig. 1) are shown in table 1 . The median (and interquartile range) of age and triglyceride levels are shown as they are not in normal distribution. Then those characteristics were compared between the known-cause group and the unknown-cause group using the Student's unpaired t test, the Wilcoxon rank-sum test, or the $\chi^{2}$ test. The mean serum lipase level, adjusted for sex, as well as age and creatinine level as continuous variables (which is known to influence serum lipase levels directly [19]), was compared among the known-cause and unknown-cause groups, or among the organic and functional dyspepsia groups, using multiple linear regression models. The bootstrap method with 1,000 replications was used to derive a 95\% confidence interval (CI) using the bias-corrected and accelerated method, which has been shown to be appropriate for the small sample size because of its high internal and external validity [20]. Odds ratios (ORs) for high lipase levels adjusted for age, 
Table 2. Mean lipase and p-amylase levels and proportions of patients with high lipase and high p-amylase

a Mean lipase and p-amylase levels according to the symptoms and causes of dyspepsia

\begin{tabular}{|c|c|c|c|c|c|c|c|c|}
\hline & \multirow[t]{2}{*}{ No dyspepsia } & \multirow[t]{2}{*}{ Acute dyspepsia } & \multicolumn{3}{|c|}{ Chronic dyspepsia } & \multirow[t]{2}{*}{$\mathrm{b}^{\mathrm{a}}$} & \multirow[t]{2}{*}{$95 \% \mathrm{CI}^{\mathrm{a}}$} & \multirow[t]{2}{*}{$\mathrm{p}^{\mathrm{a}}$} \\
\hline & & & known cause & unknown cause & gallstone & & & \\
\hline Lipase, U/l & $\begin{array}{c}36.3 \pm 13.7 \\
(\mathrm{n}=59)\end{array}$ & $\begin{array}{c}36.1 \pm 13.5 \\
(\mathrm{n}=31)\end{array}$ & $\begin{array}{c}35.3 \pm 12.3 \\
(\mathrm{n}=38)\end{array}$ & $\begin{array}{r}40.6 \pm 15.1 \\
(\mathrm{n}=112)\end{array}$ & $\begin{array}{c}39.6 \pm 13.7 \\
(\mathrm{n}=30)\end{array}$ & 6.0 & 1.6 to 10.4 & 0.008 \\
\hline p-amylase, IU/l & $\begin{array}{c}34.5 \pm 10.4 \\
(\mathrm{n}=57)\end{array}$ & $\begin{array}{c}36.2 \pm 10.2 \\
(\mathrm{n}=32)\end{array}$ & $\begin{array}{c}36.6 \pm 12.8 \\
(\mathrm{n}=34)\end{array}$ & $\begin{array}{r}40.1 \pm 12.0 \\
(\mathrm{n}=109)\end{array}$ & $\begin{array}{c}41.6 \pm 13.8 \\
(\mathrm{n}=30)\end{array}$ & 4.6 & -0.5 to 9.6 & 0.074 \\
\hline
\end{tabular}

Variables are presented as means $\pm \mathrm{SD} . \mathrm{b}=$ Regression coefficient.

${ }^{a}$ Comparison between the known-cause and unknown-cause group adjusted for age, sex, and creatinine using multivariate regression models using the bootstrap method.

b Proportions of patients with high lipase and high p-amylase according to the symptoms and causes of dyspepsia

\begin{tabular}{|c|c|c|c|c|c|c|c|c|}
\hline & \multirow[t]{2}{*}{ No dyspepsia } & \multirow[t]{2}{*}{ Acute dyspepsia } & \multicolumn{3}{|c|}{ Chronic dyspepsia } & \multirow[t]{2}{*}{$\mathrm{OR}^{\mathrm{a}}$} & \multirow[t]{2}{*}{$95 \% \mathrm{CI}^{\mathrm{a}}$} & \multirow[t]{2}{*}{$\mathrm{p}^{\mathrm{b}}$} \\
\hline & & & known cause & unknown cause & gallstone & & & \\
\hline High lipase & $\begin{array}{c}7(12 \%) \\
(\mathrm{n}=59)\end{array}$ & $\begin{array}{c}4(13 \%) \\
(\mathrm{n}=31)\end{array}$ & $\begin{array}{c}4(11 \%) \\
(\mathrm{n}=38)\end{array}$ & $\begin{array}{l}24(21 \%) \\
(\mathrm{n}=112)\end{array}$ & $\begin{array}{c}9(30 \%) \\
(\mathrm{n}=30)\end{array}$ & 2.6 & 0.8 to 8.2 & 0.156 \\
\hline High p-amylase & $\begin{array}{r}4(7 \%) \\
(n=57)\end{array}$ & $\begin{array}{r}2(6 \%) \\
(\mathrm{n}=32)\end{array}$ & $\begin{array}{c}4(12 \%) \\
(\mathrm{n}=34)\end{array}$ & $\begin{array}{l}19(17 \%) \\
(\mathrm{n}=109)\end{array}$ & $\begin{array}{c}7(23 \%) \\
(\mathrm{n}=30)\end{array}$ & 2.2 & 0.7 to 7.4 & 0.595 \\
\hline
\end{tabular}

High lipase: serum lipase higher than $50 \mathrm{U} / \mathrm{l}$; high p-amylase: serum pancreatic isoamylase higher than 50 IU/l.

a Comparison between the known-cause and unknown-cause group adjusted for age, sex, and creatinine using unconditional logistic regression models. ${ }^{\mathrm{b}}$ Fisher's exact method.

sex, and creatinine were estimated using unconditional logistic regression models with 95\% CIs. Fisher's exact method was used when the expected number was under 5 for any cells in the $2 \times 2$ table. STATA version 9 (STATA Corp., College Station, Tex., USA) was used for these analyses.

\section{Results}

The characteristics of the study subjects, including their symptoms and the cause of dyspepsia, are shown in table 1. There were no significant differences between the subgroups of known-cause and the unknown-cause of chronic dyspepsia in age, sex, LDL and HDL cholesterols, uric acid, iron, and the proportions of subjects with fatty liver, hypertension, diabetes mellitus and hyperlipidemia. However, the distributions of triglyceride levels were significantly different with Wilcoxon rank-sum test. The diameter of the CBD, the proportions of subjects with MPD dilatation and pancreatic degenerative changes were also not different between the two subgroups. The diagnosed causes of dyspepsia in the known-cause subgroup were gastritis $(n=17)$, gastric ulcer $(n=4)$, regurgitation $(n=3)$, duodenal ulcer $(n=3)$, enteritis $(n=2)$, and some less frequent causes $(\mathrm{n}=9$; gastric cancer, duodenitis, CBD stone, chronic hepatitis, gigantic hepatic cyst, colon cancer, irritable bowel syndrome, malignant lymphoma and angina pectoris).

The mean lipase and p-amylase levels and the proportions of patients with high lipase and high p-amylase among the three groups $(n=272)$ are shown in table $2 a, b$.

The mean lipase level and proportion of high lipase level of the known-cause subgroup were similar to those of the no dyspepsia or acute dyspepsia group, while those in the unknown-cause subgroup were as high as those in the gallstone subgroup. The mean lipase level of the unknown-cause subgroup was significantly higher than that of the known-cause subgroup (mean \pm SD, $40.6 \pm$ 15.1 vs. $35.3 \pm 12.3 \mathrm{U} / \mathrm{l}, \mathrm{p}=0.029$ ), and this difference was significant after adjustment for age, sex and creatinine $[\mathrm{b}$ (adjusted mean difference) $=6.0 ; 95 \% \mathrm{CI}=1.6-$ 
Table 3. Lipase levels in a subgroup analysis of patients with a known and unknown cause of chronic dyspepsia

\begin{tabular}{lccccc}
\hline & $\begin{array}{l}\text { Organic dyspepsia } \\
\text { (known cause, } \mathrm{n}=30)\end{array}$ & $\begin{array}{l}\text { Functional dyspepsia } \\
\text { (unknown cause, } \mathrm{n}=22)\end{array}$ & $\mathrm{b}^{\mathrm{a}}$ & $\mathrm{OR}^{\mathrm{a}}$ & $95 \% \mathrm{CI}^{\mathrm{a}}$ \\
\hline Lipase, U/1 & $35.4 \pm 11.6$ & $41.4 \pm 13.7$ & 7.1 & - & $0.2-14.0$ \\
High lipase, $\mathrm{n}(\%)$ & $3(10)$ & $5(23)$ & - & 3.7 & $0.7-20.4$ \\
\hline
\end{tabular}

a Adjusted for age, sex, and creatinine using multivariate regression models or unconditional logistic regression models.

${ }^{\mathrm{b}}$ Fisher's exact method.

$10.4 ; \mathrm{p}=0.008]$. The proportion of patients with high lipase (lipase higher than $50 \mathrm{U} / \mathrm{l}$ ) was not significantly different $(p=0.156)$ between these subgroups. The mean p-amylase level and the proportion of patients with high p-amylase were also higher in the unknown-cause subgroup than in the known-cause subgroup, but the differences were smaller than those for lipase and not statistically significant $(p=0.074$ for $p$-amylase, and $p=0.595$ for high p-amylase) (table 2a, b).

Based on the upper gastrointestinal endoscopy or upper gastrointestinal tract imaging, a higher mean lipase level was observed among patients with functional dyspepsia (derived from the unknown-cause subgroup) compared to patients with organic dyspepsia (derived from the known-cause subgroup) (mean $\pm \mathrm{SD}, 41.4 \pm 13.7$ vs. $35.4 \pm 11.6 \mathrm{U} / \mathrm{l}, \mathrm{p}=0.045$ after adjustment), and the proportion of patients with high lipase was also higher in the functional dyspepsia patients (22.7 vs. $10.0 \%, \mathrm{OR}=3.7$ after adjustment, $\mathrm{p}=0.260$ ) (table 3 ).

The total number of consultations in this clinic from July 2006 to June 2007 was 1,213 , and the expected prevalence of patients with 'mild functional pancreatic disorder' who showed high lipase or high p-amylase levels among the unknown-cause subgroup was calculated to be $3.0 \%$.

\section{Discussion}

We have shown that patients with chronic dyspepsia without any explainable cause based on an US have higher lipase levels than those with a known cause. These higher lipase levels were also observed in the functional dyspepsia patients compared with the organic dyspepsia patients. We therefore suggest that mild functional pancreatic disorder may be the cause of chronic dyspepsia with an unknown cause in some cases.
A number of studies have documented abnormal pancreatic function in patients with dyspepsia [6-10]. Our study demonstrated that a lipase level above the reference range was observed in more than $20 \%$ of patients with chronic dyspepsia without any explainable cause, which is different compared to patients with dyspepsia due to a known cause (10\%) based on the total and subgroup analysis. This result is consistent with a study that showed abnormal (either increased or decreased) pancreatic isoamylase levels in $20 \%$ of dyspepsia patients in primary care [9].

Currently, there is no appropriate diagnostic name for patients with chronic dyspepsia and slightly increased pancreatic enzyme levels, hence we would like to introduce the term 'mild functional pancreatic disorder'. Chronic pancreatitis, with pancreatic insufficiency in many cases, requires morphologic changes for diagnosis. Functional disorders of the pancreas, however, should appear before structural abnormalities [10]. Endosonography can detect mild chronic pancreatitis [21], but this diagnostic procedure is not routinely performed in general practice. Therefore probably many people have symptoms caused by 'mild functional pancreatic disorder' before structural changes can be detected by noninvasive radiographic examinations. This was demonstrated in this study as the diameter of the CBD, and the proportions of subjects with MPD dilatation and pancreatic degenerative changes were not different among patients with a known cause and unknown cause of chronic dyspepsia. Serum lipase elevation, on the other hand, had been reported to be $97 \%$ specific for diagnosing exocrine pancreatic insufficiency [22], so it seems reasonable to check serum lipase level to diagnose pancreatic disorder in case of chronic dyspepsia.

The diagnosis of functional pancreatic sphincter of Oddi (SO) disorder is based on upper abdominal pain accompanied by elevated serum amylase and/or lipase [11] and can cause idiopathic recurrent pancreatitis in the ab- 
sence of any common cause of pancreatitis (such as alcohol intake or gallstones) [23]. The clinical presentations of the functional pancreatic SO disorder resemble those of our study patients. Although the surgical procedures such as total division of the $\mathrm{SO}$ is recommended for patients with severe pancreatic SO disorder, there are no adequate diagnostic procedures and treatments for patients with milder pancreatic SO disorder. The mild functional pancreatic disorder observed in our study might be related to mild type pancreatic SO dysfunction. This hypothesis is supported by the findings that more than half of the patients with pancreatic-type pain and elevated amylase or lipase showed increased pancreatic SO pressures [24].

The difference in serum lipase levels between the known- and unknown-cause subgroups was $5 \mathrm{U} / \mathrm{l}$ in our study. The method used in this study has very good repeatability and reproducibility [17]. In chronic pancreatitis one would suspect small elevations, and so a difference of $5 \mathrm{U} / \mathrm{l}$ for lipase in patients with chronic dyspepsia is clinically important as pancreatic dysfunction may be the cause of their symptoms. Otherwise lipase levels can also rise in other disorders, such as hepatobiliary disease, inflammatory bowel disease, and chronic renal failure [25], which were excluded in this study. An additional study is needed to clarify pancreatic function in patients with dyspepsia of unknown cause.

The limitation of our study is that we lack information about Helicobacter pylori infection. Eradication of $H$. $p y$ - lori infection showed a $14 \%$ reduction of functional dyspepsia compared with placebo [26]. However, most of our patients (elder Japanese) were expected to be infected with $H$. pylori, but routine $H$. pylori testing is not recommended in older patients with dyspepsia in primary care [27].

For patients with functional dyspepsia it is recommended to consume low-fat meals and restrict coffee, alcohol and smoking to decrease the intensity of symptoms [12]. These recommendations are the same as those for patients with chronic pancreatitis. Compared with functional dyspepsia, cessation of fat consumption is not strongly recommended for gastric ulcer or gastritis. This supports a relationship between functional dyspepsia and pancreatic disorders. In this study, the physician's recommendation for cessation of fat intake in patients with chronic dyspepsia from an unknown cause could be a possible explanation for the lower triglyceride level in that group.

\section{Conclusion}

Our study demonstrated that serum lipase level was slightly but significantly higher in patients with chronic dyspepsia without any explainable cause than in those with chronic dyspepsia due to a known cause. Hence, mild functional pancreatic disorder may underlie the cause of dyspepsia in these cases.

\section{References}

1 Knill-Jones RP: Geographical differences in the prevalence of dyspepsia. Scand J Gastroenterol Suppl 1991;182:17-24.

$\checkmark 2$ Maconi G, Tosetti C, Stanghellini V, Bianchi Porro G, Corinaldesi R: Dyspeptic symptoms in primary care: an observational study in general practice. Eur J Gastroenterol Hepatol 2002;14:985-990.

>3 Haag S, Talley NJ, Holtmann G: Symptom patterns in functional dyspepsia and irritable bowel syndrome: relationship to disturbances in gastric emptying and response to a nutrient challenge in consulters and nonconsulters. Gut 2004;53:1445-1451.

4 Schwartz MP, Samsom M, Smout AJ: Chemospecific alterations in duodenal perception and motor response in functional dyspepsia. Am J Gastroenterol 2001;96: 2596-2602.

- 5 Holtmann G, Goebell H, Jockenhoevel F, Talley NJ: Altered vagal and intestinal mechanosensory function in chronic unexplained dyspepsia. Gut 1998;42:501-506.
-6 Schulze S, Thorsgaard Pedersen N, Jørgensen MJ, Møllmann KM, Rune SJ: Association between duodenal bulb ulceration and reduced exocrine pancreatic function. Gut 1983;24: 781-783.

7 Andersen BN, Scheel J, Rune SJ, Worning H: Exocrine pancreatic function in patients with dyspepsia. Hepatogastroenterology 1982;29:35-37.

8 Smith RC, Talley NJ, Dent OF, Jones M, Waller SL: Exocrine pancreatic function and chronic unexplained dyspepsia: a case-control study. Int J Pancreatol 1991;8:253-262.

-9 Skude G, Andren P, Hallert C, Kalin S, Lorentzson S, Petersson BG, Sassner P: Pancreatic disease in dyspepsia. Digestion 1987; 37(suppl 1):14-17.

10 Sahai AV, Mishra G, Penman ID, Williams D, Wallace MB, Hadzijahic N, Pearson A, Vanvelse A, Hoffman BJ, Hawes RH: EUS to detect evidence of pancreatic disease in patients with persistent or nonspecific dyspepsia. Gastrointest Endosc 2000;52:153-159.
11 Drossman DA, Corazziari E, Delvaux M, Spiller RC, Talley NJ, Thompson WG, Whitehead WE: Rome III: The Functional Gastrointestinal Disorders. McLean, Degnon, 2007, vol 3, pp 420-486, 596-638.

12 Feinle-Bisset C, Meier B, Fried M, Beglinger C: Role of cognitive factors in symptom induction following high and low fat meals in patients with functional dyspepsia. Gut 2003;52:1414-1418.

13 Talley NJ, Meineche-Schmidt V, Pare P, Duckworth M, Raisanen P, Pap A, Kordecki $\mathrm{H}$, Schmid V: Efficacy of omeprazole in functional dyspepsia: double-blind, randomized, placebo-controlled trials (the Bond and Opera studies). Aliment Pharmacol Ther 1998;12:1055-1065.

14 Malfertheiner P, Domínguez-Muñoz JE: Effect of exogenous pancreatic enzymes on gastrointestinal and pancreatic hormone release and gastrointestinal motility. Digestion 1993;54(suppl 2):15-20. 
15 Giger U, Stanga Z, DeLegge MH: Management of chronic pancreatitis. Nutr Clin Pract 2004;19:37-49.

16 Abdel Aziz AM, Lehman GA: Current treatment options for chronic pancreatitis. Curr Treat Options Gastroenterol 2007;10:355368.

17 Matsui S, Watanabe S, Koyama H, Yokota S, Kikuno A, Kitada M: Fundamental and clinical evaluation of serum lipase by new lipase measurement kit 'Lipase color' (Roche Diagnostics) (in Japanese). Jpn J Med Pharm Sci 1999;41:489-496.

18 Talley NJ: How should Helicobacter pylori positive dyspeptic patients be managed? Gut 1999;45(suppl 1):I28-I31.
19 Jiang CF, Ng KW, Tan SW, Wu CS, Chen HC, Liang CT, Chen YH: Serum level of amylase and lipase in various stages of chronic renal insufficiency. Zhonghua Yi Xue Za Zhi (Taipei) 2002;65:49-54.

20 Steyerberg EW, Bleeker SE, Moll HA, Grobbee DE, Moons KG: Internal and external validation of predictive models: a simulation study of bias and precision in small samples. J Clin Epidemiol 2003;56:441-447.

21 Catalano MF: Diagnosing early-stage chronic pancreatitis: is endoscopic ultrasound a reliable modality? J Gastroenterol 2007;42: 78-84.

22 Schmidt E, Schmidt FW: Advances in the enzyme diagnosis of pancreatic diseases. Clin Biochem 1990;23:383-394.

23 Toouli J, Roberts-Thomson IC, Dent J, Lee J: Sphincter of Oddi motility disorders in patients with idiopathic recurrent pancreatitis. Br J Surg 1985;72:859-863.
24 Linder JD, Geels W, Wilcox CM: Prevalence of sphincter of Oddi dysfunction: can results from specialized centers be generalized? Dig Dis Sci 2002;47:2411-2415.

25 Serrano N: Increased lipase plasma levels in ICU patients: when are they critical? Chest 2005;127:7-10.

26 McColl K, Murray L, El-Omar E, Dickson A, El-Nujumi A, Wirz A, Kelman A, Penny C, Knill-Jones R, Hilditch T: Symptomatic benefit from eradicating Helicobacter pylori infection in patients with nonulcer dyspepsia. N Engl J Med 1998;339:1869-1874.

27 Cardin F, Zorzi M, Bovo E, Guerra C, Bandini F, Polito D, Bano F, Grion AM, Toffanin R: Effect of implementation of a dyspepsia and Helicobacter pylori eradication guideline in primary care. Digestion 2005;72:1-7. 